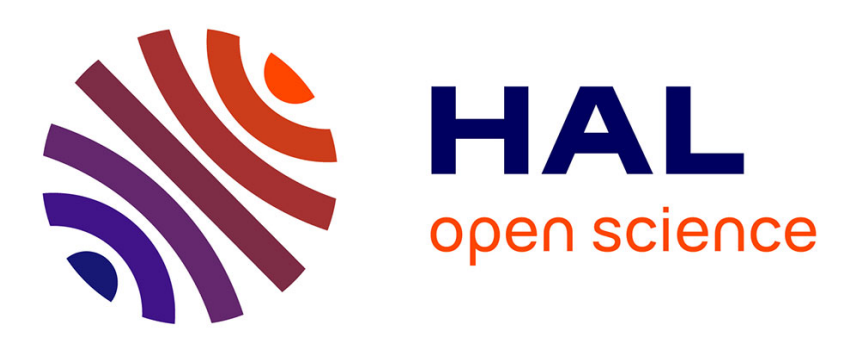

\title{
Estimation of subject-specific ligament length variation during knee flexion
}

Elena Bergamini, Hélène Pillet, Goulven Rochcongar, Patricia Thoreux, Wafa Skalli, Aurelio Cappozzo, Philippe Rouch

\section{- To cite this version:}

Elena Bergamini, Hélène Pillet, Goulven Rochcongar, Patricia Thoreux, Wafa Skalli, et al.. Estimation of subject-specific ligament length variation during knee flexion. Computer Methods in Biomechanics and Biomedical Engineering, 2015, 18, pp.1888-1889. 10.1080/10255842.2015.1069556 . hal-02569382

\section{HAL Id: hal-02569382 \\ https://hal.science/hal-02569382}

Submitted on 11 May 2020

HAL is a multi-disciplinary open access archive for the deposit and dissemination of scientific research documents, whether they are published or not. The documents may come from teaching and research institutions in France or abroad, or from public or private research centers.
L'archive ouverte pluridisciplinaire HAL, est destinée au dépôt et à la diffusion de documents scientifiques de niveau recherche, publiés ou non, émanant des établissements d'enseignement et de recherche français ou étrangers, des laboratoires publics ou privés. 


\title{
Estimation of subject-specific ligament length variation during knee flexion
}

\author{
E. Bergamini ${ }^{a}$, H. Pillet ${ }^{b}$, G. Rochcongar ${ }^{b, c}$, P. Thoreux ${ }^{b, d}$, W. Skallib, A. Cappozzo a and P. Rouch ${ }^{b}$ \\ aBOHNES, University of Rome "Foro Italico", Rome, Italy; 'Arts et Metiers ParisTech, LBM/Institut de Biomécanique Humaine Georges Charpak, \\ Paris, France; 'Département d'Orthopédie et Traumatologie, INSERM U1075 COMETE "Mobilité: Attention, Orientation \& Chronobiologie", \\ Université de Caen, Caen, France; 'Service de Chirurgie Orthopédique et Traumatologique, Hôpital Avicenne, Université Paris 13, Bobigny, France
}

KEYWORDS Knee ligaments; attachment sites; modeling; human movement analysis

\section{Introduction}

Detailed knowledge about subject-specific knee ligament length variation during knee flexion is crucial for musculoskeletal modeling in human movement analysis and in clinical contexts (Ascani et al. 2014). In this respect, accurate estimation of ligament origin and insertion locations is needed. Although extensive literature exists describing the ligament attachment site position ex vivo (Kopf et al. 2009), this information is hardly obtainable in vivo unless using medical imaging techniques (magnetic resonance, MRI, or computed tomography, $\mathrm{CT}$ ) that are time-consuming, expensive and, when radiation is involved, risky for the subjects. Furthermore, the identification of the ligament attachment site location using MRI may be characterized by significant inter- and intra-observer variability thus leading to errors that are too large to generate reliable subject-specific knee models (Rachmat et al. 2014). Therefore, the aim of the present study is to propose and validate a method for the accurate in vivo estimation of the subject-specific length of the major knee ligaments (anterior and posterior cruciate, ACL and PCL, medial and collateral ligaments, MCL and LCL) which does not necessarily require the use of medical imaging techniques to identify the ligament attachment sites.

\section{Methods}

\subsection{Specimens, kinematics and bone models}

Eleven specimens (age: 47-79 years), consisting of femur, patella, fibula, tibia and intact joint passive structures, were analyzed after a thawing period of $24 \mathrm{~h}$. Two clusters of markers were secured to the femur and tibia and three tantalum spheres were embedded in each bone. The specimens were set in motion (six flexion-extension cycles, range of motion: $0-120^{\circ}$ ) using the device described in Azmy et al. (2010) and the 3D pose of both bony segments were recorded with an optoelectronic system (Polaris, CA). Two orthogonal $\mathrm{X}$-ray images of each specimen were simultaneously obtained (EOS $\left.{ }^{\oplus}, \mathrm{FR}\right)$ and a 3D digital model of the tibia, fibula, and femur, including markers and tantalum spheres, was obtained using the reconstruction algorithm validated in Chaibi et al. (2012). This algorithm scales and deforms bone templates to match subject-specific X-ray images. Anatomical reference frames were then defined for the tibia and femur bone models according to Schlatterer et al. (2009).

\subsection{True and estimated ligament length variations}

Each specimen was dissected and the attachment sites of ACL, PCL, superficial bundle of MCL, and LCL were identified and marked using a radio-opaque paint composed of barium sulphate. CT scans of each bone epiphysis were taken (Philips, Best, NL) and processed to obtain the $3 \mathrm{D}$ geometry of each attachment site footprint, as well as the position of the tantalum spheres. The latter were used to perform a registration between the reference frames of the X-ray and CT scan systems, and to map the attachment sites on the corresponding subject-specific bone models. The centroids of the origin and insertion of each ligament, hereinafter referred to as true centroids $\left(x_{\mathrm{t}}\right)$, were then calculated and their $3 \mathrm{D}$ positions expressed with respect to the corresponding bone anatomical reference frame. To obtain the estimated subject-specific centroids $\left(x_{\mathrm{e}}\right), x_{\mathrm{t}}$ coordinates were first scaled and deformed using a kriging algorithm (Trochu 1993) to map each true centroid on the bone templates used in Chaibi et al. (2012), thus obtaining 11 centroids (one for each specimen) for each ligament attachment site (Figure 1).
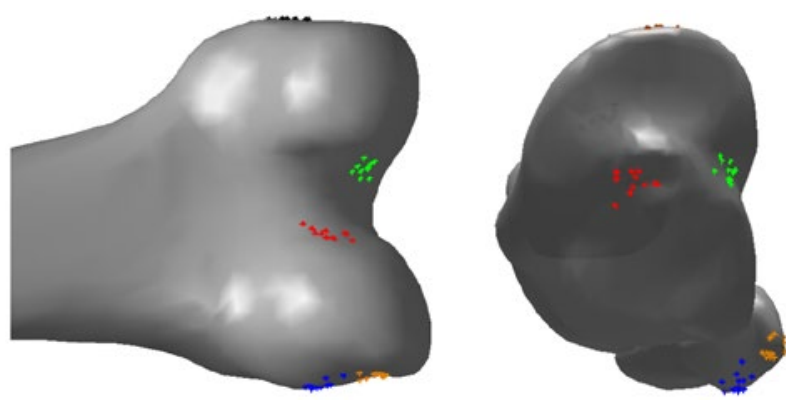

Figure 1. Femur and tibia templates with all centroids. 

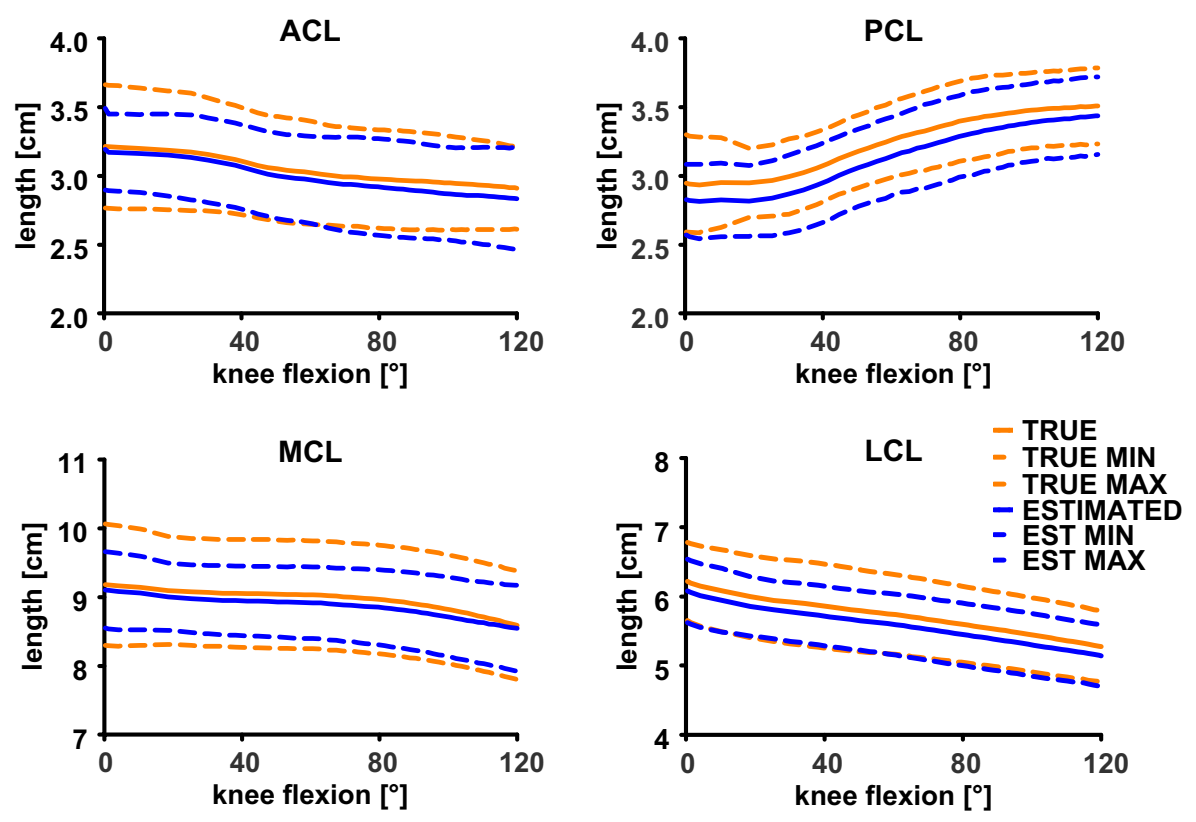

Figure 2. True and estimated ligament length variation Mean, maximum and minimum curves are depicted.

Second, the mean of 10 out of 11 centroids was computed and, following a leave-one-out cross-validation approach, the algorithm validated in Chaibi et al. (2012) was further applied to each mean centroid, thus obtaining $x_{\mathrm{e}}$. The distance between each true origin and insertion, as well as between each estimated origin and insertion (true and estimated lengths, $l_{\mathrm{t}}$ and $l_{\mathrm{e}}$, respectively), was determined for all ligaments during knee flexion-extension. To investigate if significant differences existed between true and estimated ligament lengths, the root mean square error (RMSE) and the Pearson correlation coefficient $(r)$ were computed between $l_{\mathrm{t}}$ and $l_{\mathrm{e}}$ for each ligament. In addition, a paired $t$-test (alpha level $=0.05$ ) between $l_{\mathrm{t}}$ and $l_{\mathrm{e}}$ was performed for the following flexion angles: $0^{\circ}, 15^{\circ}, 30^{\circ}, 45^{\circ}, 60^{\circ}, 75^{\circ}, 90^{\circ}, 105^{\circ}$, and $120^{\circ}$.

\section{Results and discussion}

The true and estimated length variation of each ligament during knee flexion is reported in Figure 2. RMSEs between $l_{\mathrm{t}}$ and $l_{\mathrm{e}}$ were lower than $0.2 \mathrm{~mm}$ for all ligaments. Strong correlations were found for all ligament length pairs $(r>0.7)$. Finally, no significant difference $(p>0.1)$ was found between $l_{\mathrm{t}}$ and $l_{\mathrm{e}}$ for all ligaments at all considered knee flexion angles.

These results indicate that the proposed method allows to accurately estimate the subject-specific length variation of the major knee ligaments during knee flexion-extension. This was done by matching bone template models, embedding the coordinates of each ligament attachment site centroids, to individual bones. The subject-specific morphological information needed to perform this matching, obtained in the present work using low dose $\mathrm{X}$-rays, can also be derived in vivo by acquiring partial features of the bones through manual palpation of bony prominences (Donati et al. 2007), therefore without the use of any medical imaging techniques.

\section{Conclusions}

The present study proposes and validates a methodology for the estimation of the subject-specific length variation of the four major knee ligaments. This methodology, which has the advantage of not necessarily requiring the use of medical imaging techniques to identify the subject-specific ligament attachment sites, allows to accurately estimate the ligament lengths during knee flexion-extension in vivo, provided that the kinematics obtained is accurate and reliable. This information can lead to individualized and realistic musculoskeletal knee models to be applied either in human movement analysis or in clinical contexts.

\section{Acknowledgements}

The contribution of Ann-Laure Pollastri and of Louis Dagneaux are gratefully acknowledged.

\section{References}

Ascani D, Mazzà C, De Lollis A, Bernardoni M, Viceconti M. 2014. A procedure to estimate the origins and the insertions of the knee ligaments from computed tomography images. J Biomech. 48:233-237.

Azmy C, Guérard S, Bonnet X, Gabrielli F, Skalli W. 2010. EOS orthopaedic imaging system to study patellofemoral kinematics: assessment of uncertainty. Orthop Traumatol Surg Res. 96:28-36.

Chaibi Y, Cresson T, Aubert B, Hausselle J, Neyret P, Hauger O, de Guise JA, Skalli W. 2012. Fast 3D reconstruction of the lower limb using a parametric model and statistical inferences and clinical measurements calculation from biplanar X-rays. Comput Methods Biomech Biomed Eng. 15:457-466.

Donati M, Camomilla V, Vannozzi G, Cappozzo A. 2007. Enhanced anatomical calibration in human movement analysis. Gait Posture. 26:179-185.

Kopf S, Musahl V, Tashman S, Szczodry M, Shen W, Fu FH. 2009. A systematic review of the femoral origin and tibial insertion morphology of the ACL. Knee Surg Sports Traumatol Arthrosc. 17:213-219.

Rachmat HH, Janssen D, Zevenbergen WJ, Verkerke GJ, Diercks RL, Verdonschot N. 2014. Generating finite element models of the knee: how accurately can we determine ligament attachment sites from MRI scans? Med Eng Phys. 36:701-707.

Schlatterer B, Suedhoff I, Bonnet X, Catonne Y, Maestro M, Skalli W. 2009. Skeletal landmarks for TKR implantations: evaluation of their accuracy using EOS imaging acquisition system. Orthop Traum Surg Res. 95:2-11.

Trochu F. 1993. A contouring program based on dual kriging interpolation. Eng Comput. 9:160-177. 